\title{
SIMULATION IN MANUFACTURING PLANNING OF BUILDINGS
}

\author{
Fritz Berner \\ Vitali Kochkine \\ Institute of Construction Management \\ University of Stuttgart \\ Pfaffenwaldring 7 \\ 70569 Stuttgart, GERMANY
}

\author{
Ilka Habenicht \\ Sven Spieckermann
}

\author{
SimPlan AG \\ Edmund-Seng-Straße 3-5 \\ 63477 Maintal, GERMANY
}

\author{
Cornelius Väth \\ Institute of Economical and Technical Real Estate \\ Management - IWTI GmbH \\ Curiestraße 2 \\ 70563 Stuttgart, GERMANY
}

\begin{abstract}
Optimal planning of construction projects requires an efficient allocation of available resources. Labor, material, equipment are to be planned, coordinated and quickly adapted to varying conditions. Frequent (design) changes during the construction period, diversity of trades and the high complexity of interacting processes in building manufacturing require innovative ways to support process-influencing decisions - a tool which allows testing interventions and adjustments in the manufacturing process, including individual sub-processes with the best possible efficiency. In this context, the discrete-event simulation comes into place. A research group simulated the manufacturing process of a hotel project in all details in order to examine applicability of simulation in the construction industry and to scrutinize and adjust it according to the construction specifics. The approach taken, the challenges encountered and insights gained will be presented in this article.
\end{abstract}

\section{FUNDAMENTALS}

\subsection{Design Phase of Buildings}

In order to realize a project successfully, an integrated and well-considered planning is essential. The understanding of the term "planning" within the AEC industry usually considers only the building design. The client commissions architects and engineers to design a building. They create the geometric shape of the building, choose the needed materials and roughly estimate cost. The definitions of the scope of work and the corresponding work phases of the German Fee Regulation for Architects and Engineers can be used as a template for the different planning steps.

In addition, all laws and regulations for the manufacturing of buildings must be taken into account. The design varies in detail depending on project size and type. If there are no changes or additions during the further project development, the building design is usually very dedicated and consistent. Deficits occur in details only occasionally, for example, if the understanding among designers is insufficient. Designers add corresponding specifications to the building design to complete it. Then, the design task is supposed to be fulfilled sufficiently. 
For the success of the project it is necessary, that not only the design of the final product is understood as detailed planning. The building production has to be considered during the design process as an integral part. However, with a few exceptions this overall consideration does not take place. It is assumed, that contractors appointed for the production of the building know where, when and especially how to work in detail. Construction is a composition of a complex logistic system of people, machinery, tools and materials, which can potentially cause unnecessary costs, a longer construction period and lower quality during the implementation (Berner and Väth 2011). At this point, the manufacturing planning starts.

\subsection{Potential of Manufacturing Planning in Construction Industry}

The unique character of buildings makes a transfer of the applied manufacturing process on other construction projects difficult (Berner 1983). The planning process is usually considered to be completed after being carried out once, so the site management becomes responsible to plan the real demand for staff and resources in detail, to respond in the short term to unforeseen events by spontaneous compensatory measures and to evaluate impact of such events on contract claims (Kochkine 2012). Also the manufacturing planning must be adapted to each new product individually. Due to the uniqueness of the product, a high level of automation would not prove to be effective and assembly and logistics processes are often performed primarily manually.

There is usually a high time and cost pressure during the design phase as well as during the construction period. On one hand, this decreases the time for an in-depth design phase, but on the other hand, it requires a well-prepared construction execution, which definitive is a conflict. It should be therefore analyzed on each project for every individual case, to what extent a gain in efficiency can be expected with additional expenses during the planning phase.

Experiences from other industries dealing with the production of one-of-a-kind products show, that a dedicated planning of manufacturing processes enables significant opportunities, if the required data basis can be created. The manufacturing planning can start with the first steps of product design and should intend to adopt further details later. The validity of manufacturing planning increases according to the level of detail of the product design and leads to a reliable representation of the production process at the end.

During the strategic planning a manufacturing process can be described only roughly. The first statements about allocation of resources and process durations can be already made at this stage. These statements can be enriched with details delivered by later specifications and converted into an exact resource allocation plan. This helps, to decrease the number of unexpected incidents significantly. Reactions to disturbances caused by external impacts can be coordinated in a better way, which supports the operative manufacturing management. Thus, the individual processes are coordinated in terms of use of resources and timing. As a result, an overall smooth production process is in the focus of interest instead of the preferences of the individual parties.

Also the logistics of the entire production site including its individual production units is considered in a broader context, which helps to avoid collisions and conflicts (Krauß 2005).

In order to leverage the mentioned advantages the generation and processing of a large amount of data in comparatively short time is required. Therefore, IT-based solutions might be more practicable and convenient compared to the manual handling of data. These IT-solutions have to be able to represent the entire production process, including the dynamic interaction of its sub-processes. In this context, discreteevent simulation can support the manufacturing planning.

\section{EXPERIENCES FROM THE APPLICATION OF SIMULATION IN ONE-OF-A-KIND PRODUCTION}

Discrete-event simulation is used in many industries as an established method for analyzing production and logistics processes within manufacturing planning (Wenzel 2009). It is an approved tool in all phases of planning and implementation of production and logistics (Böhnlein 2004). Simulation is applied in this 
context according to the following definition (VDI Guideline 3633, Part 1): "Simulation is the representation of a system with its dynamic processes in an experimentable model to reach findings which are transferable to reality."

In the environment of one-of-a-kind production, the use of simulation is complicated by the characteristics described in the previous section. Therefore, in one-of-a-kind production, especially in the construction industry, simulation still plays a minor role (Spieckermann 2011). It has to be mentioned though, that the development of simulation methods in one-of-a-kind production has been pushed forward in the recent past.

As a specific application the use of simulation in shipbuilding can be mentioned as an important reference. A shipbuilding company based in Flensburg, Germany, (Flensburger Schiffbaugesellschaft mbH \& Co. KG - FSG) already use simulation on own shipyard in almost every manufacturing area and at different stages of planning and implementation. At the FSG, the production of each ship is planned in detail and supported by simulation. This way, productivity and delivery performance could verifiably be increased (Steinhauer 2006).

Figure 1 (Steinhauer 2011) shows the range of different applications of simulation at FSG. Using simulation in early planning phases shows, whether the milestones are going to be met and bottlenecks exist within the process. Thus, it is possible to test different process options. Based on the results, the production engineer can choose the best one among them.

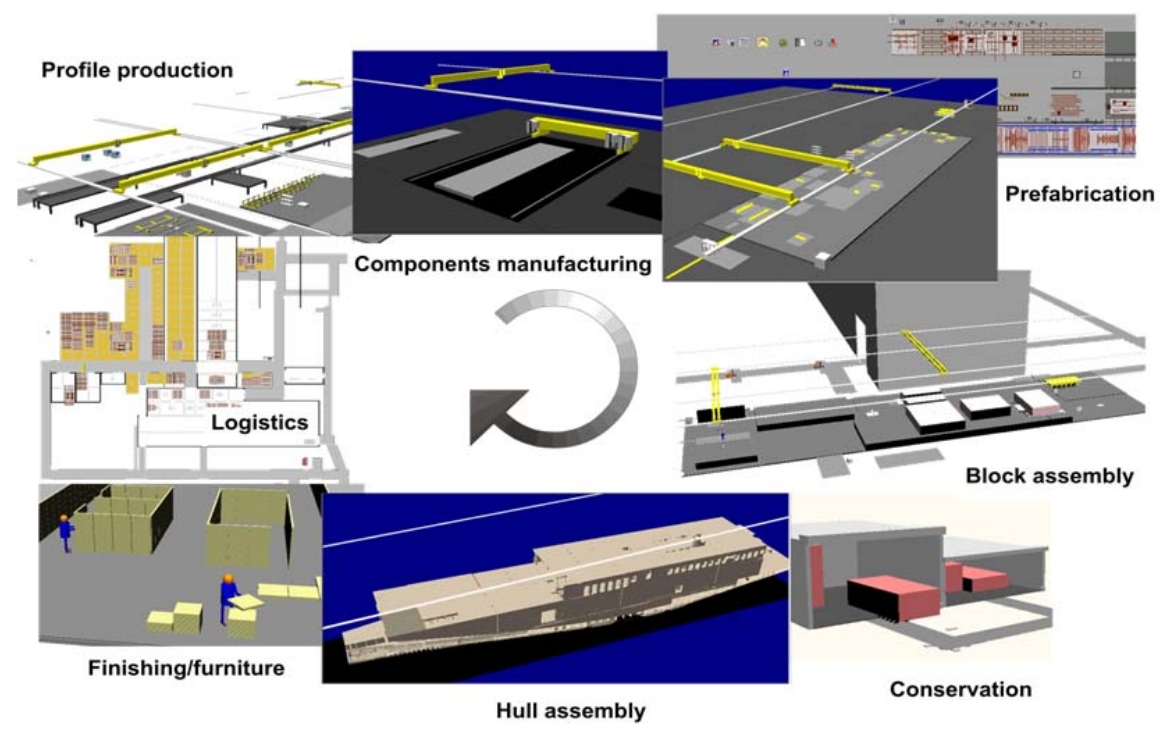

Figure 1: Application of Simulation in shipbuilding.

Another important application in addition to the simulation-based planning is the use of simulation as a management tool during operations. In cases of deviations from the plan, the consequences and their impact on the future construction process can be demonstrated at an early stage. Another result of the operative simulation is delivering the resource allocation plans.

A simulation databank provides all required data, which is based on design data, schedules, personnel data, and all other necessary information (Steinhauer 2006). The data can and must be provided at the desired level of detail and for the relevant categories.

An important condition for the successful application of simulation in the various areas of planning, work preparation and during operations is an integration of simulation in the company processes, which requires an acceptance by the management. A simulation team has been working at FSG for more than ten years in this constellation. The employees in the planning and manufacturing department, who use the 
simulation software, are trained by the simulation team. This helps significantly to achieve a wide-ranging acceptance of simulation.

\section{SIMULATION IN THE CONSTRUCTION PROCESS}

\subsection{Range of Applications of Simulation in Manufacturing Planning}

The example of FSG demonstrates that an application of simulation within one-of-a-kind production is possible in various areas. Within construction projects the application of simulation is identified primarily in the manufacturing planning (Ailland and Bargstädt 2008). Thus, the simulation can already be used during the tendering phase, for instance to generate and validate time schedules, to examine logistic concepts and to identify bottlenecks based on quantities and time assumptions.

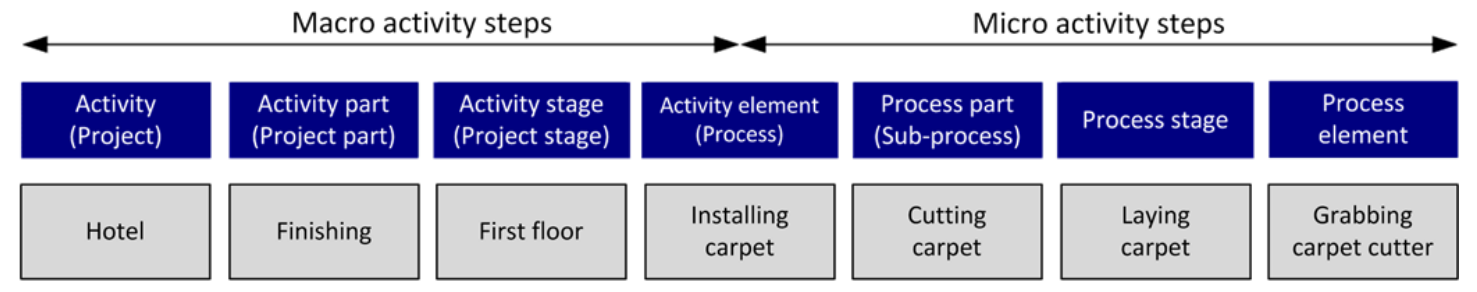

Figure 2: Process part and process stage by REFA (Berner 1983, REFA Association 1985).

Further objectives are focused within the detailed manufacturing planning. Precise daily schedules can be generated. Based on these schedules, the allocation of labor or other resources can be planned. Applying this kind of planning, the alignment and the constraints between the sub-processes must be considered (cf. Figure 2). The constraints come from the geometry of the building or from technological restrictions. Also, the use of resources for individual subtasks is analyzed. Thus, the following aspects can be considered by means of simulation:

- Determination of the working segments (on a daily basis);

- Review and assessment of alternative construction methodologies, for example alternative sequences of production steps or alternative production concepts with different resources requirements;

- Determination of the daily demand for labor and resources;

- Review of alternative logistic concepts in the context of a dynamic environment; and

- Identification of bottlenecks.

By this means, the process of value creation is structured to optimize its performance. At the same time, non-value adding activities are avoided and reduced to the greatest possible extent. As a consequence, an optimized use of resources can be reached. To achieve this target, it is necessary to have an indepth knowledge of the sub-processes as well as a clear understanding of the process links and constraints which determine the overall outcome (Girmscheid and Kersting 2011).

\subsection{Procedure during a Simulation Study}

An important aspect for the successful application of simulation is the acceptance of the simulation results by all partners in a project, who are not simulation experts in most cases. Therefore, it is important to choose a procedure which is comprehensible for non-experts, too. Hence, the research group called "Simulation in Production and Logistics" of the ASIM (Association for Simulation in the Society of Informatics) has been working on the improvement of quality of simulation studies during the recent years (Wen- 
zel 2009). In this context, a procedure model for the execution of simulation studies has been developed, which is shown in Figure 3 (Rabe, Spieckermann, and Wenzel 2008).

The flowchart shows the steps defined for modeling and collecting data. The steps are executed iteratively. For each step a sufficient documentation is required in order to increase the transparency of the procedure within the simulation study. Another important aspect to increase the credibility of the simulation models and the results of such studies is the permanent verification and validation of the results of each step.

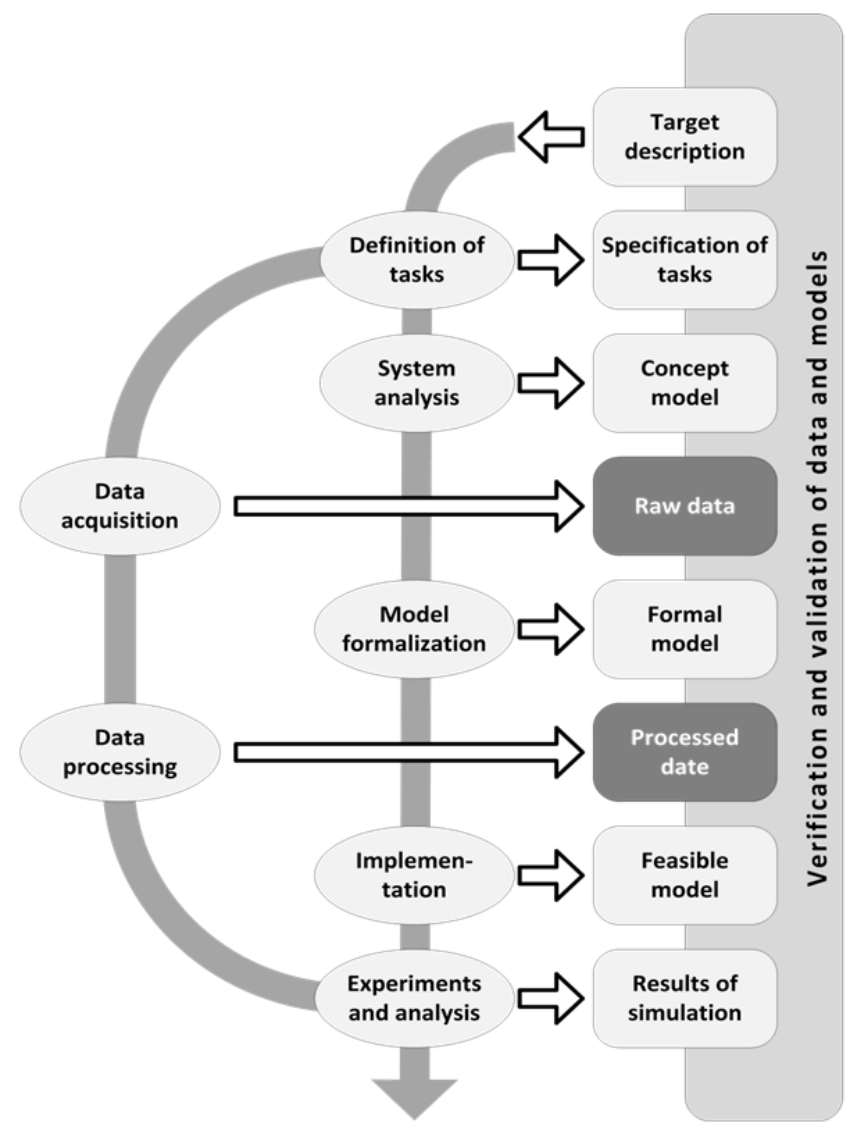

Figure 3: Flow chart for conducting simulation studies.

A condition to conduct the simulation study successfully is an accurate description of the objectives. The task description is derived from these objectives. Here, the following points are considered:

- Scope of the model,

- Level of detail,

- Reporting of results.

At the beginning, it has to be defined, which processes are taken into account in the simulation and how accurately this needs to be done. Prior to the implementation of the simulation model, the considered processes are analyzed and described. This system analysis deals intensively with the processes of the construction project. Consequently, the following issues have to be addressed:

- the sequence of the individual process steps,

- the allocation of resources or 
- restrictions, that arise, e.g., from the environment of the construction site.

In manufacturing planning such restrictions are for example the permitted construction periods or traffic restrictions that have an impact on logistics. The system analysis usually requires a close interaction between the parties, who are aware and in charge of the procedures on the construction site on one side, and the simulation experts modeling the processes on the other side. The result of the system analysis is a so-called concept model which fully describes the simulation model. Subsequently, the concept model is formalized. That means the individual processes as well as the defined restrictions are derived from the concept model and are specified in a formal way (using e.g. pseudo-code or UML etc.). The formal model is the basis for the implementation of the simulation model.

Parallel to the modeling process (from system analysis to implementation), data must be provided for the simulation study. The necessary data is derived from the corresponding task specification. For buildings this comprises: (1) the building (for example represented by its BIM data), (2) the resources, (3) the manufacturing processes, and (4) the restrictions.

The data for the building is produced during the design stage. Ideally, it requires no additional editing for further processing in the simulation model. The resources in particular are labor, building materials, machinery, construction equipment, building auxiliaries and other materials to erect the designed building. To plan manufacturing in detail, data about the manufacturing process is essential and has to be available. This data is: durations of individual steps (process parts by REFA, cf. Figure 2), territorial organization of the steps (working places), minimum and maximum amount of labors within the crews and space needed for transport, storage and processing. To represent the manufacturing process, the aforementioned data have to be linked by constraints. These are technological or manufacturing dependencies (such as hardening of concrete or the sequence of construction activities), capacity-related and safetyrelated dependencies.

Based on key figures of the building, the process of manufacturing can be reproduced, varied and optimized in a simulation study. In order to generate different alternatives, scenarios can be compared by changing and adapting individual characteristics such as type and number of available resources.

\subsection{Simulation Results}

The results of a simulation depend on the individual objective defined for the simulation study. For instance, the start or end of individual processes can be determined taking into consideration limited resources and their dependencies. Based on this data, the practicability of the existing schedules can be verified by simulation. Alternatively, schedules can be created using the simulation. The level of detail in these schedules depends on the level of detail of the modeled processes.

Another possible result is the capacity utilization rate of workforce or other resources (construction machinery, site facilities, etc.). The results of the simulation can be used as a starting point for an operational plan of personnel and other resources. Furthermore, bottlenecks can be identified and eliminated early.

\section{MANUFACTURING PLANNING AS DATA SOURCE FOR SIMULATION}

\subsection{Requirements for Application of Simulation in Manufacturing Planning}

One of the main arguments against the use of simulation for manufacturing planning in the construction industry is that the data acquisition and therefore the modeling are too work-intensive. An important condition for the application of simulation is a satisfying efficiency in the acquisition and modeling of data.

Various approaches have been developed for simulation in the construction industry. Franz (Franz 1999) presents an approach for the simulation of construction processes using Petri nets. In this context, 
Petri nets are used to model the dependencies between the various processes. A second simulation approach is based on agent-based modeling (Kugler and Franz 2008).

Another approach is the so-called constraint-based modeling which is applied in the construction sector (König et al. 2007). The execution of the process steps is subject to various restrictions (time restrictions, sequence, material and resource availability). These restrictions are expressed in the model on the basis of so-called constraints, distinguishing between hard and soft constraints. Hard constraints are used for the expression of mandatory and necessary restrictions such as technologically required sequences. Soft constraints can be used to analyze different scenarios and strategies.

Based on this modeling concept, reusable models can be created for the simulation of building production. These models can operate at different levels of detail and therefore, they are applicable at different stages of manufacturing planning.

For an efficient modeling of the building production, tools or process templates have to be used, requiring only minor adjustments to suit to the individual projects. For example, a modular library such as Simulation Toolkit Shipbuilding (STS) meets these conditions. The FSG developed the STS and applies it in their simulation projects. It is based on the simulation tool called "Tecnomatix Plant Simulation" by the software vendor Siemens PLM. The process templates of the STS have been further developed in cooperation with the Ruhr-University Bochum, the SimPlan AG and the Bauhaus University Weimar for its application in the construction industry.

\subsection{Required Data and Data Sources}

The buildings data can be differentiated in generally valid (general) and project-specific data. General data remains valid independent of the project, whereas project-specific data needs to be adjusted to every single project.

In the early planning stages the lack of precision in the project-specific data can be accepted, if the expectations with respect to the simulation results are still met sufficiently. During the planning progress an on-going specification of project-specific data takes place, thus the results of the simulation increase their accuracy, scope and reliability gradually.

Figure 4 shows project-specific data, defining material, quantity, geometry and position of the individual components of a construction project. This data varies from project to project. The basis for project-specific data is drawings, building models and also the specifications of the work preparation, site installation and site layout.

\begin{tabular}{|c|c|c|c|c|}
\hline \multirow{2}{*}{ Type of data } & \multicolumn{2}{|c|}{ Project-specific data } & \multicolumn{2}{|c|}{ General data } \\
\hline & Example & Source & Example & Source \\
\hline Object data & $\begin{array}{l}\text { Properties of structural } \\
\text { components: } \\
\text { - Material } \\
\text { - Quantity } \\
\text { - Geometry } \\
\text { - Position }\end{array}$ & $\begin{array}{l}\text { - Drawings } \\
\text { - Plans } \\
\text { - Building models } \\
\text { - Preparation of work } \\
\text { - Site drawings }\end{array}$ & $\begin{array}{l}\text { - Composition of } \\
\text { common structural } \\
\text { components }\end{array}$ & $\begin{array}{l}\text { - Catalogs } \\
\text { - Reference literature } \\
\text { - General literature } \\
\text { - Product-specific } \\
\text { CAD-catalogs }\end{array}$ \\
\hline Process data & $\begin{array}{l}\text { - Position of storing } \\
\text { areas } \\
\text { - Access paths } \\
\text { - Technology } \\
\text { adjustments } \\
\text { - Special dependencies }\end{array}$ & $\begin{array}{l}\text { - Manufacturing } \\
\text { planning }\end{array}$ & $\begin{array}{l}\text { - Performance factor } \\
\text { - Dependences } \\
\text { - Needed working space } \\
\text { - Labor } \\
\text { - Scaffolding, auxiliary } \\
\text { and construction } \\
\text { materials }\end{array}$ & $\begin{array}{l}\text { - Reference literature } \\
\text { - General literature } \\
\text { - Company archives }\end{array}$ \\
\hline
\end{tabular}

Figure 4: Types of data in construction.

In contrast, general object data, such as common composition rules of individual components, remains constant from project to project. This general object data can be found in product catalogs, standard 
drawing details, literature and in reference books. This data can be considered given for every construction project and usually meets requirements of simulation.

Some process data, such as rates, dependencies between process parts, required work spaces, minimum number and minimum qualification of necessary labors and the required auxiliary and construction materials, is also valid throughout the projects. However, the previously mentioned production rates are typically not accurate enough, since they are only available for complete processes such as the shuttering of walls. In order to represent the manufacturing process in detail and meaningfully in a simulation study, knowledge about the production duration for process parts is essential. The general process data, except for the production rates, can also originate from the literature or from company own archives. In order to collect real reference values for these rates, time measurements on construction sites must be undertaken.

The general process data is complemented by project-specific process data like the location of storage areas or access routes. Project-specific process data, such as technology adjustments or special dependencies, must be created or determined in the context of manufacturing planning. Technology adjustments imply adopting values such as production rates to the assumed, changed or real project conditions. This may be a substitution of normal concrete for self-compacting concrete. Specific dependencies can be e.g. creation of noise barriers under ongoing railway operation, which cannot be derived from generally valid dependencies.

The sheer quantity of required data results in a significant collection effort to for a simulation study. The available data shown origins from different sources and varies in quality.

\section{CASE STUDY}

\subsection{Application}

The potentials of simulation application in the construction industry were examined in a case study. The objective was to explore the benefits and limitations of simulation in manufacturing planning. For the simulation study, the finishing process of a multi-story hotel has been modeled. The upper floors are designed in a similar way and they have three types of rooms, which vary in size and fit-out.

The finishing process of the rooms is characterized by the same processes. The duration of these processes and their sub-processes depends on the type of room. The individual work steps have been carried out by workers from different companies. Using the simulation, the number of necessary workers and the operating times for each company were determined. A special restriction in this example is the availability of space inside each room: operations like "screeding" have the effect, that no other activities can be executed in this room at the same time. However, only a part of the room is blocked during other operations. In this case, several activities can take place simultaneously, if necessary.

\subsection{Data Acquisition for the Case Study}

The considered construction project was already completed when the case study started. Therefore, the entire documentation of the building as well as the existing process planning was accessible to the research group. The whole project data was available. However, the collection of required process data turned to be much more difficult than expected before the project started (cf. data matrix in Figure 4). Despite the large amount of available information about the construction process, such as schedules and site $\operatorname{logs}$, the required input data for the simulation could be generated only to a limited extend. The quality of the data was found to be inadequate and the information was not detailed enough. This problem was revealed most clearly during the sub-process analysis of the construction. The subdivision of the processes into individual sub-processes afterwards was still possible on the basis of experience of project participants, but even the involved site managers struggled to name the production rates, the need for space and labor for these individual process parts. For example, only the activity production rate for laying carpet per square meter was known. The rates of the separate sub-processes "cleaning", "cutting", "gluing", "cut- 
ting off the insulation" or "attaching mopboards" were unknown. Such a detailed analysis of data is currently not common in the AEC industry and does not belong to the general knowledge.

Suggestions and reasonable assumptions according to the available process data were made in order to generate these details needed for the simulation study. For that purpose the actual duration of the processes were broken down to the level of the sub-processes (REFA Association 1985). This information was collected in large databases and applied in the simulation model.

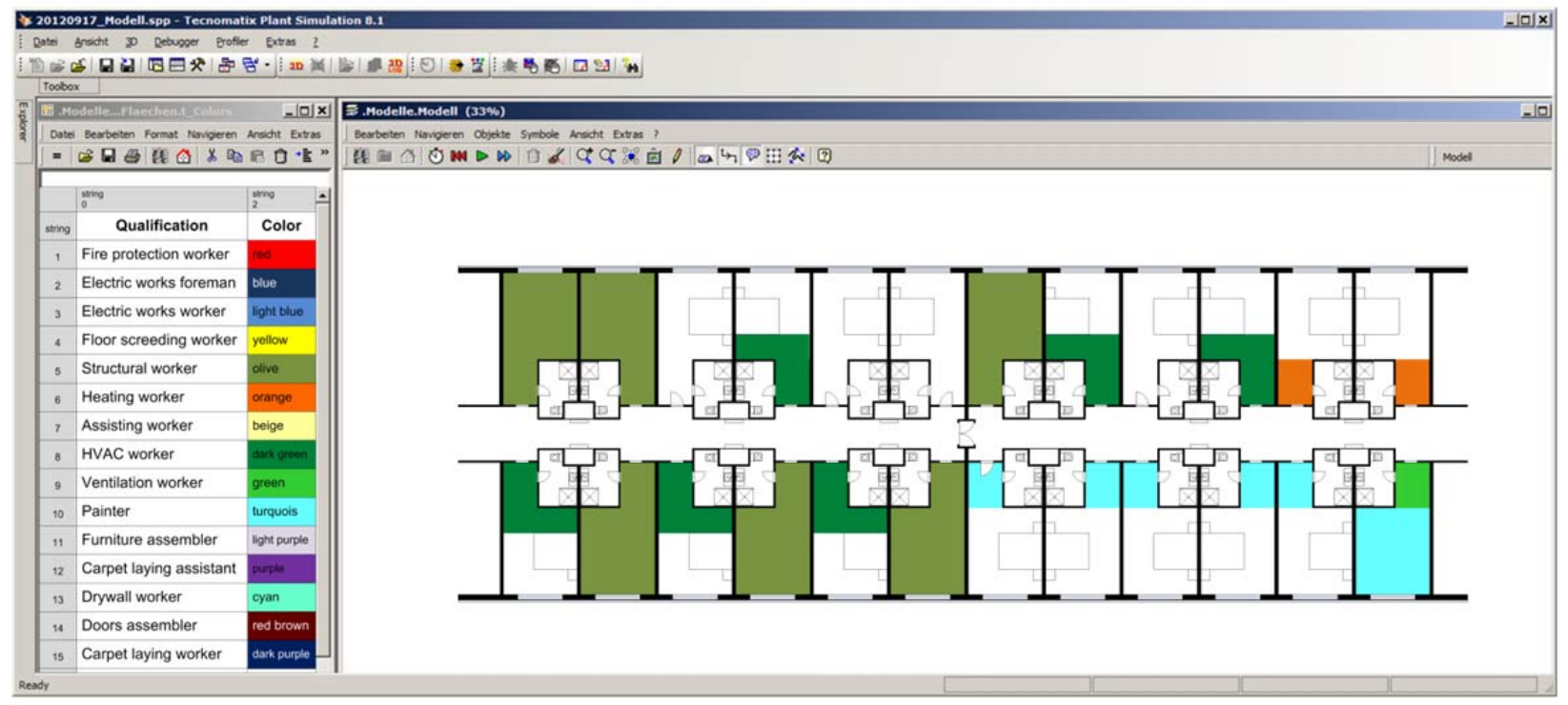

Figure 5: Screenshot of an instantaneous working areas assignment in the simulation model.

\subsection{Execution of Simulation Study}

The model was created using the process library STS (see section 4.1). The data has been integrated through a spreadsheet-based interface, followed by the modification according to the required data structure for the modeling process. By an easy and quick data extension this model is applicable to several floors and rooms. Figure 5 shows an example of the occupation of work areas in a part of a story of the simulation model.

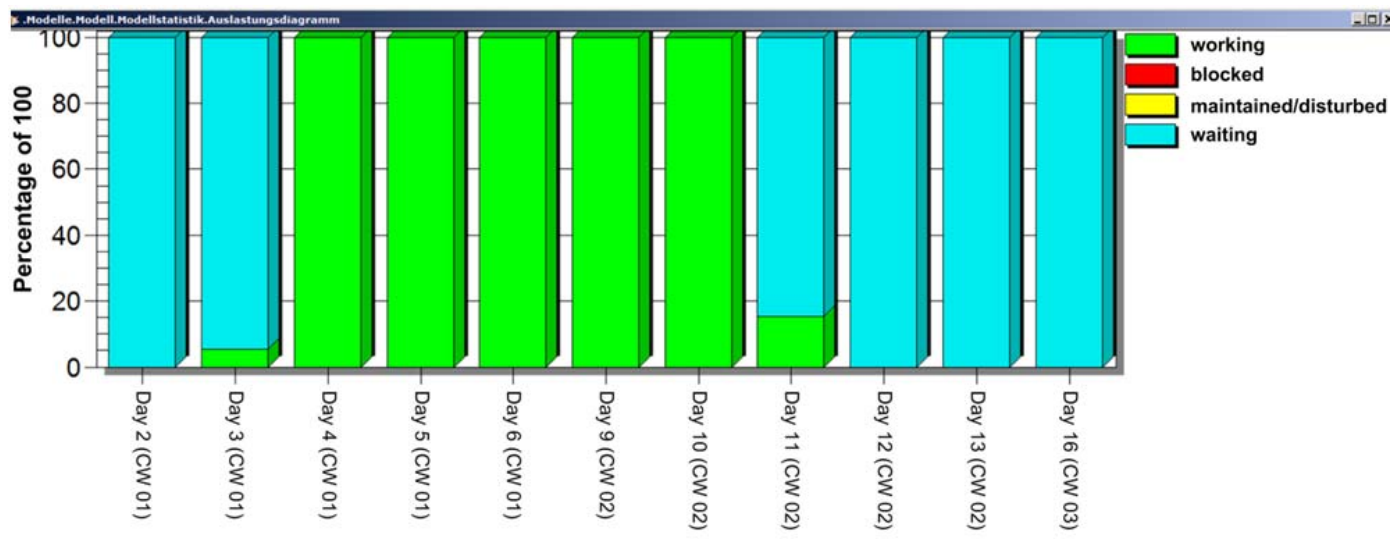

Figure 6: Daily main activity rate of electrical subcontractor (REFA Association 1985). 
During the execution of each process part, the sequencing constraints for the finishing as well as the available labor resources are taken into consideration. For this purpose required areas in the room are reserved. This can be animated in the model (cf. Figure 5). The reserved areas are color-coded accordingly, with each color showing the respective work being performed in the area.

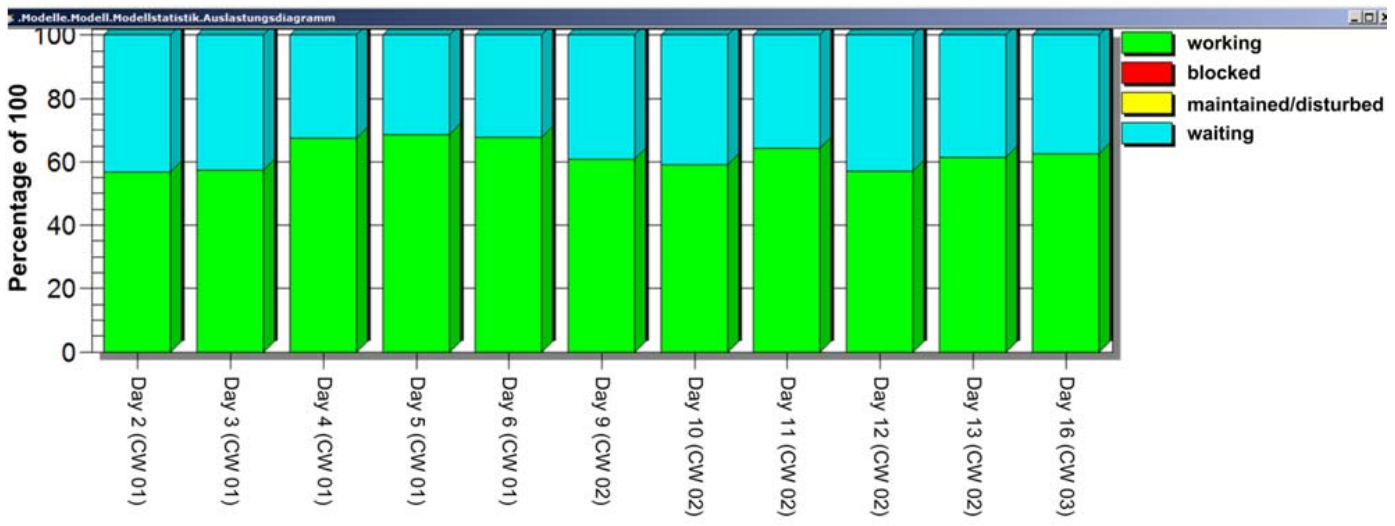

Figure 7: Daily main activity rate of the drywall subcontractor (REFA Association 1985).

The work utilization rate of single labors or for each company is tracked in the model. So it can be determined when and how many workers of a company are required weekly, daily or hourly. Figure 6 shows the utilization of a company, which is fully busy only on five days, whereas Figure 7 shows an example of a company busy for the entire period, but its capacity is only utilized up to $60 \%$. Another result of the simulation is the information when and where the individual processes or sub-processes are executed. This is illustrated in a Gantt chart and may be included in scheduling. In this first phase of the case study, it was assumed in the model, that the necessary materials are always available on-site and at the working areas. Therefore, in a further step the model should be extended by including a logistics concept. Thus, the deliveries to the story and intermediate storage in the rooms and hallways could be included into the model.

\section{CONCLUSION AND OUTLOOK}

As indicated in the introduction, manufacturing planning is usually not applied in the construction industry. This is justified by the lack of a systematic analysis of the process, the high complexity of construction projects and the considerable effort, which would be necessary for the detailed planning of the production (Girmscheid and Kersting 2011). Besides, there are concerns, that the efficiency of a superior manufacturing planning is questionable, due to the limited impact on the participating contractors and their independent work preparation (Mikulakova et al. 2010).

However, experience from other industries shows, that an in-depth and superior manufacturing planning is definitely useful even in the one-of-a-kind production environment. It makes the complexity of the one-of-a-kind production manageable in the design phase and controllable in the production phase. By exploiting simulation, the manufacturing planning gains reliability and credibility. Furthermore, different scenarios can be analyzed within simulation studies. The most appropriate option can be selected from different construction sequence variants and the construction process of buildings can be planned in the most favorable way. Thus, the simulation represents an essential tool to support the construction production during the manufacturing planning and execution phase.

The conducted simulation study has shown, that the necessary process input data for such a detailed manufacturing planning does not exist in practice today. Collection of this data for the purposes of simulation is a substantial and very important task in order to generate the benefits for construction production. 
The experience gained from the sample project shows the close relationship between assembly and logistics, which has already been recognized and consciously controlled in other industries for a long time. Especially in the detailed planning phase, the logistics processes and their impact on the production of the building should not be underestimated. Therefore, the processes of construction logistics in the context of manufacturing planning have to be considered at the same level of detail as the construction processes. This fact should be taken into account by an extensive logistics simulation, applied to the sample project.

In this article it was demonstrated, that the technical solutions for construction simulation are available and the necessity is obvious. For how long can the construction industry neglect this improvement?

\section{REFERENCES}

Ailland, K., and H.-J. Bargstädt. 2008. "Tagesgenaues Termincontrolling auf Baustellen mit Hilfe der Simulation." In Advances in Simulation for Production and Logistics Applications Edited by M. Rabe, 171-178. Stuttgart: Fraunhofer IRB Verlag.

Berner, F., and C. Väth. 2011. "Der Grundstein der Kostensicherheit - Baubetrieb als Basis für die Erstellung von Leistungsverzeichnissen." In Festschrift anlässlich des 60. Geburtstages von Univ.-Prof. Dr.-Ing. Rainer Schach, Edited by P. Jehle. Dresden: A-Z Druck.

Berner, F. 1983. "Verlustquellenforschung im Ingenieurbau." Ph.D. thesis, Institute of Construction Management, University of Stuttgart.

Böhnlein, C.-B. 2004. "Simulation in der Bauwirtschaft." In Experiences from the Future - New Methods and Applications in Simulation for Production and Logistics. Proceedsings of the 11. ASIM conference "Simulation in Production und Logistics" Edited by Mertins K., and M. Rabe, 1-22. Stuttgart: Fraunhofer IRB-Verlag.

Franz, V. 1999. "Simulation von Bauwerken mit Hilfe von Perti-Netzen." In Frontiers in Simulation. Tagungsband zum 13. Symposium Simulationstechnik Edited by G. Hohmann. Ghent: SCS European Publishing House.

Girmscheid, G., and M. Kersting. 2011. "Rational schalen.” In Bauingenieur 02/2011, 50-51. Dusseldorf: Springer-VDI-Verlag.

König, M., U. Beißert, D. Steinhauer, and H.-J. Bargstädt. 2007. "Constraint-based Simulation of Outfitting Processes in Shipbuilding and Civil Engineering." In 6th EUROSIM Congress on Modeling and Simulation CD-ROM publication.

Kochkine, V. 2012. "Fertigungsplanung als Erfolgsfaktor der baulichen Produktion." In FortschrittBerichte VDI, Reihe 4 Nr. 218, 23. Assistententreffen der Bereiche Bauwirtschaft, Baubetrieb und Bauverfahrenstechnik, Edited by M. F. Brunk, R. Osebold, 25-34. Proceedings of the conference at RWTH Aachen University, 18.-20. Juli 2012, Dusseldorf: VDI Verlag.

Krauß, S. 2005. "Die Baulogistik in der schlüsselfertigen Ausführung." In Schriftenreihe des Instituts für Baubetriebslehre der Universität Stuttgart, Band 45, Edited by F. Berner. Berlin: Bauwerk-Verlag.

Kugler, M., and Franz, V. 2008. "Einsatz von Simulation zur Effizienzsteigerung von Produktionsprozessen im Bauwesen." In Advances in Simulation for Production and Logistics Applications, Edited by M. Rabe, 151-160. Stuttgart: Fraunhofer IRB Verlag.

Mikulakova, E., M. König, E. Tauscher, and K. Beucke. 2010. "Knowledge-based schedule generation and evaluation." In Advanced Engineering Informatics 24/2010, 389-403. Elsevier.

Rabe, M., S. Spieckermann, and S. Wenzel. 2008. "A New Procedure Model for Verification and Validation in Production and Logistics Simulation." In Proceedings of the 2008 Winter Simulation Conference, Edited by S.J. Mason, R.R. Hill, L. Mönch, T. Jefferson, and J.W. Fowler, 1717-1726. Piscataway, New Jersey: IEEE Press.

REFA Verband für Arbeitsstudien und Betriebsorganisation e. V. 1985. Methodenlehre der Planung und Steuerung. Teil 2, 4. Auflage. Munich: Hanser. 
Spieckermann, S. 2011. "Simulation von Unikatprozessen aus Sicht eines Spezialisten für Simulationsdienstleistungen." In Tagungsband des 1. BBB-Kongresses, Edited by R. Schach, 141-151. Dresden

Steinhauer, D. 2006. "Simulation im Schiffbau - Unterstützung von Werftplanung, Produktionsplanung und Produktentwicklung bei der Flensburger Schiffbau-Gesellschaft." In Simulation in Produktion und Logistik. Proceedings of the 12. ASIM conference Edited by S. Wenzel, 1-14. San Diego: SCS Publishing House e.V.

Steinhauer, D. 2011. "The Simulation Toolkit Shipbuilding (STS) - 10 Years of Cooperative Development and Interbranch Applications." In COMPIT'11, Proceedings of the 10th International Conference on Computer and IT Applications in the Maritime Industries, Edited by V. Bertram, 453-465. TU Hamburg-Harburg.

VDI e.V. 2000. "Richtlinie 3633, Blatt 1: Simulation von Logistik-, Materialfluss- und Produktionssystemen, Grundlagen." In VDI-Handbuch Materialfluss und Fördertechnik Bd. 8, Gründruck. Beuth: Berlin.

Wenzel, S. 2009. "Modellbildung und Simulation in Produktion und Logistik - Stand und Perspektiven." In Proceedings of ASIM conference STS/GMMS, Edited by G. Elst, 7-16. Stuttgart: Fraunhofer IRB Verlag.

\section{AUTHOR BIOGRAPHIES}

FRITZ BERNER is professor in the Institute of Construction Management at the University of Stuttgart. His research interests are strategic controlling of construction companies, construction logistics and Public Private Partnerships. In 2001 he initiated a new study program Real Estate Engineering and Real Estate Management. He is a member of the Association of German Engineers (VDI), Verband Deutscher Architekten- und Ingenieurvereine e.V., and the REFA-Association of Baden-Württemberg. His email address is fritz.berner@ibl.uni-stuttgart.de and his web page is https://www.ibl.uni-stuttgart.de.

ILKA HABENICHT is simulation consultant at SimPlan AG. She studied computer science in economics at the Ilmenau University of Technology and worked there as research associate. She received her doctoral degree from the University of Hagen before joining SimPlan 2006. Her email address is ilka.habenicht@simplan.de and the web page of the company is http://www.simplan.de.

VITALI KOCHKINE is research associate in the Institute of Construction Management at the University of Stuttgart. His research is focused on manufacturing planning and simulation in construction production and logistics. He holds a Diploma degree in civil engineering and economics from the Technical University of Kaiserslautern. His email address is vitali.kochkine@ibl.uni-stuttgart.de and his web page is https://www.ibl.uni-stuttgart.de.

SVEN SPIECKERMANN studied Business Informatics at the Darmstadt University of Technology and wrote his dissertation at the Braunschweig University of Technology. He worked for SimPlan as Consultant and Project Manager for Simulation and runs the company as CEO today. He is also visiting lecturer for simulation at the TU Braunschweig and the TU Darmstadt. His e-mail address is sven.spieckermann@simplan.de and the web page of the company is http://www.simplan.de.

CORNELIUS VÄTH is managing director of the Institute of Economic and Technical Real Estate Management - IWTI GmbH and responsible for the cost reliability sector. He holds a Diploma in civil engineering and received his Ph.D. from the University of Stuttgart where he holds lectures now. His research field is claim management and analysis of balance sheets of consolidated building companies. His e-mail address is vaeth@iwti.de and his web page is http://www.iwti.de. 